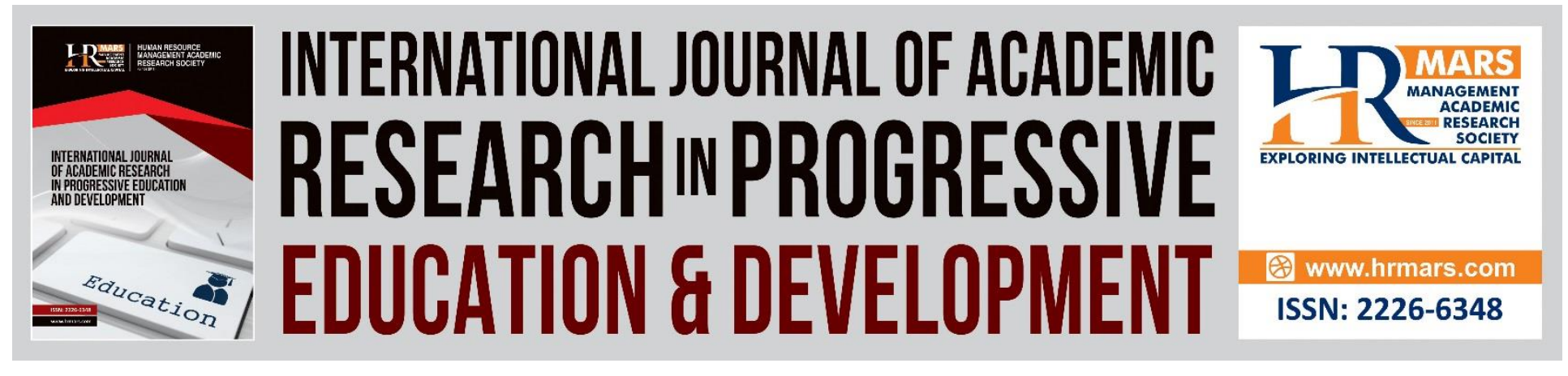

\title{
Sociocultural Analyses of Malaysia's Orang Asli Preschoolers and Computers: A Qualitative Case Study
}

Mohamad Ibrani Shahrimin Adam Assim, Yasmin Yaccob, Nurul Hidayu Mat Jusoh

To Link this Article: http://dx.doi.org/10.6007/IJARPED/v9-i3/8029

DOI:10.6007/IJARPED/v9-i3/8029

Received: 11 October 2020, Revised: 03 November 2020, Accepted: 28 November 2020

Published Online: 07 December 2020

In-Text Citation: (Assim et al., 2020)

To Cite this Article: Assim, M. I. S. A., Yaccob, Y., \& Jusoh, N. H. M. (2020). Sociocultural Analyses of Malaysia's Orang Asli Preschoolers and Computers: A Qualitative Case Study. International Journal of Academic Research in Progressive Education and Development, 9(3), 145-159.

Copyright: (C) 2020 The Author(s)

Published by Human Resource Management Academic Research Society (www.hrmars.com)

This article is published under the Creative Commons Attribution (CC BY 4.0) license. Anyone may reproduce, distribute, translate and create derivative works of this article (for both commercial and non-commercial purposes), subject to full attribution to the original publication and authors. The full terms of this license may be seen at: http://creativecommons.org/licences/by/4.0/legalcode

Vol. 9(3) 2020, Pg. 145 - 159

http://hrmars.com/index.php/pages/detail/IJARPED

JOURNAL HOMEPAGE

Full Terms \& Conditions of access and use can be found at

http://hrmars.com/index.php/pages/detail/publication-ethics 


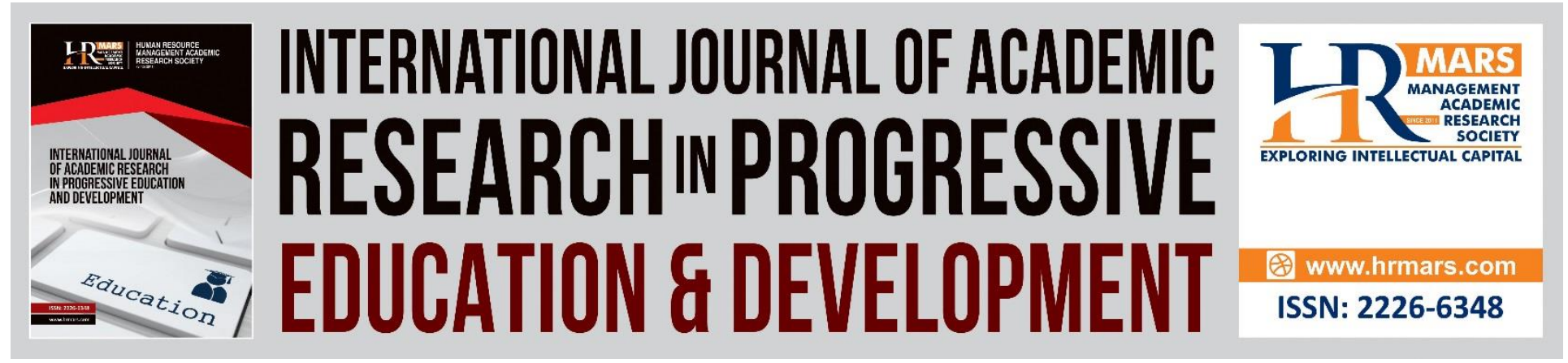

\title{
Sociocultural Analyses of Malaysia's Orang Asli Preschoolers and Computers: A Qualitative Case Study
}

\author{
Mohamad Ibrani Shahrimin Adam Assim, Yasmin Yaccob, Nurul \\ Hidayu Mat Jusoh \\ Faculty of Humanities, Management and Science, Universiti Putra Malaysia Bintulu \\ Campus, Sarawak, Malaysia \\ Email: ibrani@upm.edu.my
}

\begin{abstract}
This study examined the patterns of socioculturally appropriate social interactions of Malaysia's Orang Asli children in an educational computer environment. Rogoff's Sociocultural Theory and the three foci of analyses were utilized in this study. A multi-method case study design was employed to identify the patterns of socioculturally appropriate social interactions unique to the Malaysia's Orang Asli preschool children in Selangor. Twelve preschool children were observed and interviewed using a semi-structured questionnaire. Seven dominant interaction patterns related to socioculturally appropriate social interactions of Orang Asli preschool children were examined. Factors facilitating and inhibiting the social interactions were identified using the application of Rogoff's three foci of analyses and series of semi-structured interviews with Malaysian preschool teachers and Orang Asli preschool children. Rogoff's Sociocultural Theory and the three foci of analyses may present a more and thorough view of indigenous children's understanding of an educational computer environment.
\end{abstract}

Keywords: Sociocultural Analyses, Orang Asli Preschoolers, Social Interactions, Computer, Qualitative Case Study.

\section{Introduction}

As the world moves beyond the millennium and societies become more diverse with globalisation, implementation of multicultural perspectives in educational settings cannot be challenge and debated any more (Smagorinsky, 2012). Doyle \& Woods (2018) and Bhavnagri \& Gonzalez-Mena (1997) contends that educators cannot afford to dishonour the diversity present in early childhood settings, disregard cultural variations, and in fact, allow the gap between home and school cultures to widen. The choice and selection of pedagogical approaches of educators 
appear to be grounded in their cultural traditions and knowledge (Eriks-Brophy et al., 2008; McAlpine et al., 1996). Thus, it is important to note that along with teachers, learners too are equally swayed by their cultural goals and meanings, which in turn mediate their learning and impact on their learning processes (Abulencia, 2015; Broadfoot, 1998).

This study is guided by a sociocultural perspective. Central to this perspective is the notion that children's cognition, and their preceding actions, are constructed and constantly evolving because of social interaction environment or culture (Johnston et al., 2020; Rogoff, 1994). Edwards (2000), as cited in Watkins et al. (2017) postulate that the sociocultural perspectives emphasize relationships between people, actions, contexts, meanings, communities, and cultural histories. Furthermore, the sociocultural perspective seeks to describe the appropriate classroom computer integration by examining how the phenomenon is experienced and exhbited through the children's collaborative interactions. It is hoped that by enabling the researcher to build a model of social interaction pattern as it relates to computer integration among Orang Asli preschool children, it will also be possible to construct an image of how these interactions, and the nature of the classroom itself, are linked to the larger sociocultural context of the participants.

A mismatch between cultures and teaching styles may lead to learning difficulties, confusions over identity, lowered motivation and under academic achievement of children of ethnic minorities (Syed, 2017; Matthews, 1996). Thus, an examination of social and cultural contexts in which learning is embedded is critical for addressing the inequalities in school-related outcomes, particularly within the computer learning environment, for children from diverse backgrounds. The purpose of this study is to investigate and identify the socioculturally appropriate social interaction patterns exhibited by Malaysia's Orang Asli preschool children in an educational computer environment.

\section{Literature Review}

To support the country's ICT master plan and in line with the country's drive to the digital economy, the education system has to be transformed (MCMC, 2016; MCMC Survey, 2017 ; MOE, 1998; NITC, 2001). An example of a previous catalyst for this MCMC transformation was the ICTenabled Smart Schools (MMC, 2017; MOE, 1998; NITC, 2001). In addition to the Smart School project, the Malaysian Ministry of Education had attempted to reduce the digital divide that exists in the different parts of the country by providing computer laboratories to thousands of schools (MCMC, 2016; NITC, 2002). Other ICT-related projects involve the training of teachers, school administrators and other school staff (MOE, 1998; NITC, 2001). Innovative projects like the use of electronic books and e-learning were also implemented to ensure their feasibility before any roll-out to all the schools in the country (MCMC, 2017; NITC, 2002). Nongovernmental agencies are also very much involved in the drive to introduce ICT into schools (MCMC, 2017; NITC, 2001).

The current study employs comparisons across communities (indigenous and non-indigenous children contexts) and using quantitative as well as qualitative approaches. Howard, (2010; 
2020); Rogoff et al. (1993; 2002) acknowledge that both quantitative and qualitative tools are important towards understanding the nature of cultural processes. Rogoff et al. (1995) argue that "close analysis of small numbers of cases can be used to compare larger numbers of cases while retaining the meaningful relations among interrelated aspects of the functioning of each case or each community studied" (p. 221). The authors stress that the analysis tools should be tailored to questions, rather than allowing customary tools to limit research questions or allowing the assumptions on which they are based to organise our own conceptions of how the phenomena themselves function (Rogoff et al., 1995; Howard, 2020).

Therefore, it is critical not to contemplate mechanistic assumptions, which prioritise control of freestanding variables, to exclude the study of dynamic, multifaceted cultural configurations (aRogoff et al., 1995). On the other hand, it is also noted that variables can be regarded as providing a shorthand reference for the sake of temporary focus on a limited set of features of cultural phenomena, in which variables as analytic tools in holistic analyses require interpretation in the light of other aspects of cultural processes (Rogoff et al., 1995). However, Howard (2010:2020) and Rogoff et al. (1995) stress the imperative of maintaining the analytic tool not to be freestanding, but in greater focus than the other aspects of the phenomena under study. Thus, it is acknowledge that the basis of the analytical model of the current study is partially premised on the functional pattern analysis, as suggested by Winegar and Valsiner (2013) and Gauvain \& Rogoff (1973), which were applied in the study of (Rogoff et al., 1993). According to Rogoff \& Toma (1997), functional pattern analysis examines generalities or patterns in a variety of similar cases (for example, individuals, dyads, classrooms, events) while attempting to maintain the meaning of individual actions in their (see Mehan, 1979; Wellman \& Estes (1986), as cited in Rogoff et al. (1993). The summaries of the analyses are as follows (Rogoff et al., 1993):

1. The focus of functional pattern analysis is to unfold development of purposive acts within ongoing events. In relation to the categories involved, in which are functionally defined, the purposes of the event are viewed as a whole, and no steps are taken to define any superficial behaviours independently and separated from their context.

2. The nature of examinations involves the contributions of participants in the context of those of other individuals, in which the evidence for constructing an account of participants' goals is available in the communication of participants.

3. Statistical methods are employed to analyse existing patterns, and employment of the examination of graphical arrays that allow tracking across multiple variables to examine patters of interrelations and to account for anomalous or similar cases.

With the advent of the fourth industrial revolution and the shift to a new economic paradigm comes also a shift in the way work is carried out due to the increasing importance of information technologies (ICTs) in work activities (Zin et al., 2013; MCMC, 2017; MOE, 1998; NITC, 2001). Malaysian Ministry of Education (MOE) had highlighted that the need for the education system to be based on two elements: creativity and innovation, as the enablers to equip the citizens towards the high-income level. The policy paper in the documents of the Blueprint on Enculturation of Life-Long Learning for Malaysia 2011- 2020 (2011), supports the need for independent and self-managed learning. With the advances in technology and growth of information, the delivery of knowledge needs to be more flexible in linking the learners with the 
learning resources (MCMC, 2016). Hence, as computers are becoming an integral part of Malaysian early childhood education, with the importance of social interaction and discourse with others in extending Orang Asli children's learning, it is imperative to investigate the sociocultural appropriateness of collaborative computer social interactions in their naturalistic classroom setting.

\section{Methodology}

This research employed a multi-method research design. The research paradigm was primarily qualitative in nature, but a quantitative component was also employed "as a convenience for analysis, not a reflection of the organization of the world or the only appropriate way to focus research on complex processes" (Rogoff et al., 2002, p. 217). The present study conducted a multiple case study (Denny, 1978; Stenhouse, 1981; Yin, 1994) of six pairs of Orang Asli preschool children, whilst engaged with the computer in dyads, within the naturalistic classroom environment. It was conducted within a naturalistic inquiry paradigm (Guba et al., 1981) involved the use of both inductive and interpretative data analysis. It is acknowledge that the basis of the analytical model of the current study is partially premised on the functional pattern analysis, as suggested by Gauvain \& Rogoff (1973) which were applied in the study of Rogoff et al. (1993). The analytical model also acknowledges the study by Mercer (1994) and the System for Observation of Children's Social Interactions (SOCSI) by Brown et al. (1996). The three foci of analysis by Rogoff $(1995,1998,2003)$ : personal, interpersonal, and community or contextual planes, is acknowledged as a major contribution towards developing the model of analysis. Originally referred to as planes of analysis (Rogoff, 1997, 1998), it is argued the underpinning assumption is that within sociocultural activity, people, contexts, actions, meanings, communities and cultural histories are all mutually constituted Rogoff et al. (2002).

Thus, using Rogoff's sociocultural perspectives delineates the analytic approach as not to examine only the child, as a single unit of analysis, nor a group of children, as if in a vacuum (Rogoff, 2003). She points out that the three foci of analysis may present a more complex and thorough view of children's understandings (2003), where she emphasise that while one of the lenses may be in sharply defined, the others remain involved but in the background $(1995,1998)$. The data analysis had revealed patterns unique to the sociocultural context of Malaysia's Orang Asli preschool children at the personal, interpersonal, and community or contextual perspectives. The identification of such interaction patterns may lead to a greater appreciation of the connection which exists between appropriate computer integration into early childhood education, and the larger society. Thus, it is argued that an overarching assumption of this study is that the sociocultural scripts play a major role in identifying inherent values within a diverse society.

\section{Results}

To illustrate Rogoff's ideas of the three foci of analysis and the transformation of participation perspective, a series of images from the findings are presented in the results section of this paper. In Figure 1 below, an image is shown without any research lens or focus of observation. The image depicts an example of a computer session undertaken in a Malaysian rural preschool classroom environment. Each child was paired in dyads, and has their own mouse device, utilising 
a collaborative software program. As shown on the image below, one of the children was initially not interested with the activity, where she maintained to observe other children (two girls at the computer- on top left corner of Figure 1) for a prolonged duration of time (approximately 18 minutes of the computer session).

Figure 1: An image of a preschool computer environment

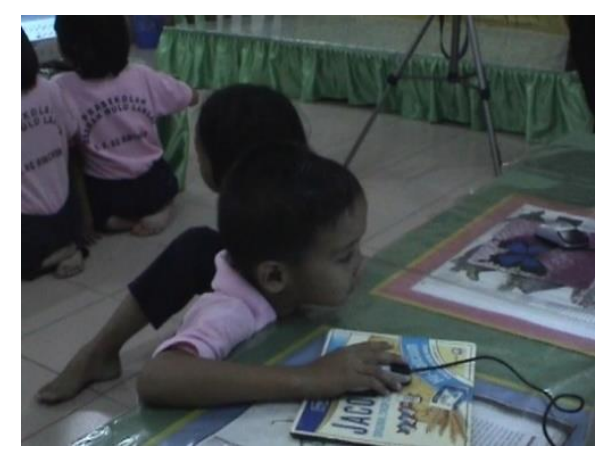

(Source: Qualitative data of current study)

This child is an Indigenous Malaysian - Orang Asli child and was reported by the classroom teacher to be a keen observer of novice activities in the class. However, in relation to the analytic model of the current study, the research lens of the three foci analysis by Rogoff $(1995,1998,2003)$ were adapted when the child begins to participate within the dyadic context of the computer environment, which involves the observation of her partner under the guidance of the teacher assistant, thus initiating the process of transformation of participation in her immediate context (see Figure 2).

Figure 2: Community or contextual focus of analysis (adapted from Rogoff, 1997, 1998) or cultural-institutional aspects of analysis (Rogoff, 2003)

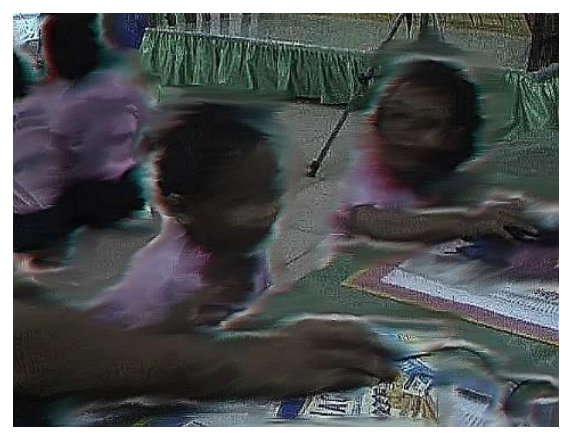

(Source: Qualitative data of current study)

Based on these adaptations of the three foci of analysis, Rogoff (2003) stress that:

"Together, the interpersonal, personal, and cultural-institutional aspects of the event constitute the activity. No aspect exists or can be studied in isolation from the others. An observer's relative 
focus on one or the other aspect can be changed, but they do not exist apart from each other" ( $p$. 58)

However, Rogoff (2003) also warns that failure to recognise culture together with the "equally important role of the people who constitute cultural activities" (p. 61) may pose certain limitations and analytical problems. Figure 3 portrays a problem that is common in many studies, where Rogoff argues that "it does not make sense to try to study cultural processes without considering the contributions of people involved, keeping them in the background of a focus on cultural, institutional community processes" (Rogoff, 2003, p. 61):

Figure 3: Research lens that recognise culture, but without people who constitute the cultural activities (Rogoff, 2003)

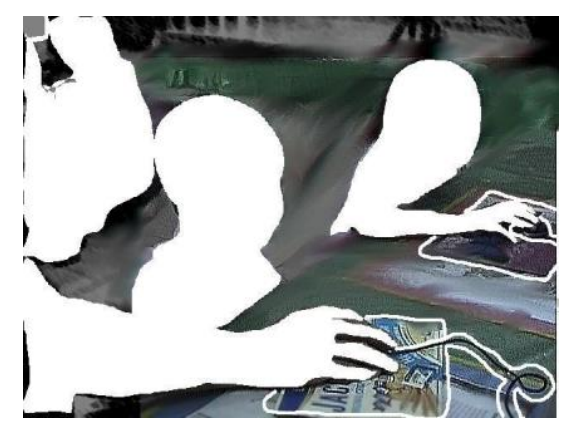

(Source: Qualitative data of current study)

Thus, this study acknowledges the view that individual, social and cultural processes are interrelated (Rogoff, 1995, 1998), and adapt the proposed use of the three foci of analysis (Rogoff, 1995, 1998) as the analytical model of the current study.

\section{Discussions}

Four cases were analysed, and seven dominant patterns emerged from the interaction analyses. Case 1, Case2, Case 3 and Case 6 were analysed and identified the interactions patters as: Asking for information/explanation; Directing partner's actions; Providing information/explanation; Terminal response; Defending control; Showing displeasure; and, Defending competence. A positive environment for collaboration was identified within two cases, which were Case. 2 and Case 5 , in contrary to Case 3 and Case 6 which exhibited the interaction patterns of conflictual behaviours, which may inhibit collaborative interaction among children.The fact that children had to demand and seize control from their peers has important implications for the effective functioning of collaborative activities in early childhood settings. This conflictual situation is more apparent when the group of children involves indigenous and non-indigenous students.

Further interaction analyses report that high status children (high socio-economic background) appear to initiate and offer guidance to their partners (for example, displaying interaction 
patterns of directing partner's actions, suggesting ideas, and providing information). These interactions were demonstrated by exhibiting high frequencies of positive behavior (as illustrated in Cases 2 and 5). The children's social goals whilst engaged with the computers were also examined. It was found that their preexisting computer competencies and attitudes, and mutual friendships among their classmates and peers are associated with the patterns of interactions exhibited. All Orang Asli respondents have similar low socio-economic backgrounds, thus demonstrated less computer competencies. This study found that the current behavioral patterns has implications towards the effective integration of computer technology into early childhood settings.

The concept of cultural apprenticeship in the frame of socialisation practices mediated by cultural traditions and norms is supported by the results presented in the literature review section. For instance, the differential use of linguistic acts and contrasting guidance patterns among Malaysian children's social interactions in this study, typically resonated their own cultural values and beliefs. The directive speech of Malaysian teachers reflects interactions orientations to guidance and role segregation between adults and children. Interestingly, this was also exhibited by the Malaysian Malay and Orang Asli children's interactions whilst engaged at the computer. In contrast, the explanatory discourses that characterised the socioculturally-sensitized teacher's expectations and the children's interactions appear to convey the cultural preferences for expression of views and scope for individual expression. Although the current study examines a different context of interactions, the variations in discourse orientations of Malaysian children and their respective teachers are partially similar to the differences in discourses of rural and urban families, that reflected their cultural orientations of 'interdependence' and 'independence' respectively (Martini, 1996; Crossley \& Watson, 2003; Ismail, 2007).

The use of directives in Malaysian teacher's expectations on the children's collaborative assistance further implied the age based hierarchical approach to guidance. Age and gender are the ordering principles of the hierarchical system of traditional Orang Asli and Malay-Malaysian society and family. Formal superiority of people is established through the age differences and men and adults, in general, have greater authority than women and children (MOE, 2016; Morris et al., 2005; Soto et al., 2011). The principle of a hierarchical ordering of social dependencies is pervasive, even today, in every aspect of social interaction.

Malaysian teachers mentioned that adult control in children's problem-solving was essential for sustaining children's attentiveness on tasks as well as sharing children's task responsibilities. The Malaysian teachers' views and expectations reflected traditional Islamic philosophical notions, according to which child in the early childhood years is considered as a gift of God, to be welcomed, cared, and indulged (MOE, 2016; Hashim \& Langgulung, 2008; Sulaiman et al., 2014). Furthermore, Malaysian teachers valued modelling as an important form of adult guidance. There was more emphasis on fostering children's explicit thought processes combined with affective processes of guidance (e.g., emotional appeals and use of endearments). In the process of collaborative guidance, the more socioculturally-sensitized Malaysian teachers' expectations of their students were that they tended to rely on modelling techniques and encourages their peers to learn through repetition. The selection of demonstration as a method of guidance by Malaysian children seems to coincide with their willingness to assume greater share of 
responsibilities among the students and their peers in their problem-solving tasks, whether they be physical or collaboratively cognitive in nature.

Similarly, the teachers' views of encouraging individual responsibility and providing guidance upon requirement reflected their cultural beliefs and goals of child development that value development of individuality in children. These beliefs were clearly exemplified in the following statement of a preschool teacher from a rural preschool centre in Selangor, Malaysia, who mentioned that:

'Children need encouragement. Independence needs to be promoted in them and that can be done by encouraging them to take up things on their own. Children can derive a sense of enjoyment and satisfaction if they do things on their own and on their own effort".

(Data source: Extracts from field note number 14/04)

The socioculturally-sensitized educated teacher's communication reflected an egalitarian style of guidance as well as cultural transmission of values such as choice, individuality, and encouragement of individual efforts. The use of explanations reflected a pattern of collaborative interactions that is conversational, child centred, less controlling, and more supportive of children's initiations and on-going task activities. Teachers supported children's mastery of cognitive skills through sharing of information, transmitting knowledge in explanations, and expanding on children's prior knowledge, a process that resonated child centred style of interaction. These findings are consistent with the observations of Western socioculturallysensitized communities reported in literature (Keats, 1997; McDonald, 1995; Sushila Niles, 1993; Ray \& Smith, 2010) where interactions reflected development of initiation and individuality in children and encouragement of their participation as conversational partners. Concomitant with variations in teacher's beliefs of adult and knowledgeable peer guidance and problem-solving, there were cultural differences with respect to the goals of children's development. As per the results of interviews, most Malaysian teachers' emphasised development of academic skill and a more socioculturally-sensitized teachers' emphasised development of social skills as valued goals of child development in the early school years. In their interviews, Malaysian teachers mentioned education and academic achievement as preferred goals of child development. They also regarded education as an investment in their student's future and to their happiness and economic prosperity. These views are consistent with reports in literature that documented Asian family's emphasis on formal education or academic achievement of their children (Chao, 1996; Fuligni, 1997; Anders et al., 2016).

In contrast to some Malaysian teachers' strong focus on development of academic skills in preschool and early primary-aged children, the socioculturally-sensitized early childhood teachers emphasised development of social skills as valued goals of development for preschool children. The variations in socioculturally-sensitized and non-sensitized teachers' goals of child development indicated in this investigation are consistent with the findings of other crosscultural studies where urban-based parents emphasised educational achievements and goals for young children as opposed to mainstream teachers' major expectations of social skill development (Ebbeck \& Glover, 1998; Goodnow, 1988; Papps et al., 1995; Pomerleau et al., 1991; Watkins et al., 2017; Otto, 2016). As discussed previously, the variations in teacher's preference for praise as a motivational technique also reflected cultural values associated its use. The lack of praise among peers of Malaysian Orang Asli children is due to a common classroom belief that 
praise reduces the focus of their long-term goals and be satisfied with intermittent achievements. In a socioculturally appropriate contexts on the other hand, use of praise is associated with promoting self-esteem in children, leading to its frequent use in adult interactions with young children.

Socioculturally-sensitized teachers, in contrast emphasised that they would expect the children to delegate responsibility among themselves while they interact with their peers. They further mentioned that children should take a major responsibility in their problem-solving rather than themselves. Accordingly, along with sharing of task responsibilities during the problem-solving activities, socioculturally-sensitized teachers encouraged their students, and the students are also encouraged their peers, explicitly to take responsibility in problem-solving, which could be argued, reflects the cultural value of promoting independence and individual responsibility. These findings on differential interactions and assistance and guidance of Orang Asli Malaysian children and their peers, and the views of their respective teachers reflected their cultural beliefs and values of child development and are synonymous with the observations of Gisela Trommsdorff \& Wolfgang Friedlmeier (1993) and Blake et al. (2016) who indicated that adult control of children's behaviours and adult responses to interactions are mediated by culturally based differences. As all the children in each individual Case Studies in this study came from the same classroom, their pre-existing relationships undoubtedly affected their interactions.

\section{Conclusion}

Based on the current findings of this study, several concluding remarks are presented. Firstly, as depicted in the discussion of the study, it is argued that the computer environment in an early childhood environment should be structured to engender collaboration, self-selection of problems, and exchange of information between collaborators (Nastasi \& Clements, 1993; Hoy \& Tarter, 2018). Secondly, the efficacious use of an educational computer environment, which integrates technology and collaborative learning, depends on multiple factors related to structuring of task-related and social-process variables (Nastasi \& Clements, 1993; Neil Mercer \& Fisher, 1992; Neil Mercer et al., 1999; Cho \& Tobias, 2016). Furthermore, sociocognitive conflict, or at least argument, may represent a valuable condition for progress in peer interaction situations (Littleton \& Hakkinen, 1999; Sato, 2017). As suggested and hypothesised by Crook (1995), this study had highlighted that emphasised settings that afford concrete manipulation and experimentation are as vital as the contents of teaching and learning itself. As cited in Crook (1995, p.546), "ideally, an individual's interaction with the problem domain might be witnessed by peers, who thereby more easily enter into collaborative engagement. Computers may have a special potential in creating such settings for joint activity". Hence, it is concluded that the results of the present investigation have important implications for early childhood education and practices.

\section{Implications for Early Childhood Computer Educational Settings}

The findings on the implicit forms of assistance indicated that even simple coordination and reorganisation of the physical learning environment, for example, by providing additional computer mouse-device in the Computer Time settings can enable children to facilitate their peers' cognitive thinking. The findings on situatedness of cognitive learning in peer-based 
guidance call for more teacher interventions in children's learning to support and scaffold their cognitive or collaborative learning. The importance of directives for advancing children's cognitions into higher levels of functioning through a cognitively comfortable route (indicated by the present findings) highlight the need for teachers to disassociate their use with "working class behaviours" and to employ them in their guided or scaffolded interactions.

\section{Implication for Sociocultural Theories}

Based on the findings and conclusion, and in reflecting on the local perspective of Malaysia's Orang Asli preschool children, this study has emphasized the important issue of socioculturally appropriate social interaction in collaborative guidance. The theoretical contributions of this study expanded the limited set of observations on collaborative interactions on cognitive development carried out with monocultural groups. This study also examined and discussed the findings in relation to the broader sociocultural and sociocognitive contexts that shaped and produced the interactions of the children. These social behaviours, particularly the socioculturally appropriate collaborative social interactions, did not always reflect accepted developmental theory. Hence, this highlights the need for more research to apply a model which investigates the relevance and suitability of sociocultural and neo-Vygotskian, and activity theories, in a range of socially and culturally diverse early childhood settings.

\section{Acknowledgement}

The author would like to acknowledge the preschool children, teachers and preschools involved in the data gathering for their help and generous support.

\section{References}

Abulencia, A. (2015). The Social Purposes of Learning Assessment. ATIKAN, 1(June), 105-122.

Anders, J., Jerrim, J., \& McCulloch, A. (2016). How Much Progress Do Children in Shanghai Make Over One Academic Year? Evidence From PISA. AERA Open, 2(4), 233285841667884. https://doi.org/10.1177/2332858416678841

Bhavnagri, N. P., \& Gonzalez-Mena, J. (1997). The Cultural Context of Infant Caregiving. Childhood Education, 74(1), 2-8. https://doi.org/10.1080/00094056.1997.10521906

Blake, P. R., Corbit, J., Callaghan, T. C., \& Warneken, F. (2016). Give as I give: Adult influence on children's giving in two cultures. Journal of Experimental Child Psychology, 152, 149-160. https://doi.org/10.1016/j.jecp.2016.07.010

Broadfoot, P. (1998). Quality standards and control in higher education: What price life-long learning? International Studies in Sociology of Education, 8(2), 155-180. https://doi.org/10.1080/0962021980020022

Brown, W. H., Odom, S. L., \& Holcombe, A. (1996). Observational assessment of young children's social behavior with peers. Early Childhood Research Quarterly, 11(1), 19-40. https://doi.org/10.1016/S0885-2006(96)90027-7

Chao, R. K. (1996). Chinese and European American mothers' beliefs about the role of parenting in children's school success. Journal of Cross-Cultural Psychology, 27(4), 403-423. https://doi.org/10.1177/0022022196274002 
Cho, M. H., \& Tobias, S. (2016). Should instructors require discussion in online courses? Effects of online discussion on community of inquiry, learner time, satisfaction, and achievement. International Review of Research in Open and Distance Learning, 17(2), 123-140. https://doi.org/10.19173/irrodl.v17i2.2342

Crook, C. (1995). On Resourcing a Concern for Collaboration Within Peer Interactions, Cognition and Instruction. Cognition and Instruction, 13(4), 541-547. https://doi.org/10.1207/s1532690xci1304

Crossley, M., \& Watson, K. (2003). Comparative and international research in education: Globalisation, context and difference. Routledge.

Denny, T. (1978). Story Telling and Educational Understanding. Paper\# 12 in Occasional Paper Series

Doyle, K., \& Woods, A. (2018). Digital Childhoods: Technologies and Children's Everyday Lives. In Digital Childhoods, International Perspectives on Early Childhood Education nad Development (Vol. 22, pp. 1-14). https://doi.org/10.1007/978-981-10-6484-5

Ebbeck, M., \& Glover, A. (1998). Immigrant Families' Expectations of Early Childhood. Australasian Journal of Early Childhood, 23(3), 14-19. https://doi.org/10.1177/183693919802300305

Eriks-Brophy, A., Quittenbaum, J., Anderson, D., \& Nelson, T. (2008). Part of the problem or part of the solution? Communication assessments of Aboriginal children residing in remote communities using videoconferencing. Clinical Linguistics and Phonetics, 22(8), 589-609. https://doi.org/10.1080/02699200802221737

Fuligni, A. J. (1997). The Academic Achievement of Adolescent from Immigrant Families: The Roles of Family Backgroun, Attitudes, and Behavior. Child Development, 68(2), 351-363.

Gauvain, M., \& Rogoff, B. (1973). Collaborative Problem Solving and Children's Planning Skills Individuals who are experienced in a cognitive activity may support a child's participation in a task by structuring the problem and by guid. Light Rogoff \& Gardner, 25(1), 139-151.

Goodnow, J. (1988). Parents ' Ideas, Actions, and Feelings: Models and Methods from Developmental and Social Psychology. Society for Research in Child Development, 59(2), 286-320.

Guba, G., Francisco, S., \& Weiss, J. (1981). Effective Evaluation: Improving The Usefulness of Evaluation Results Through Responsive and Naturalistic Approaches.

Hashim, C. N., \& Langgulung, H. (2008). Islamic Religious Curriculum in Muslim Countries: The Experiences of Indonesia and Malaysia. Bulletin of Education \& Research, 30(1), 1-19.

Howard, C. T. (2010). Why Race and Culture Matter. The Role of Race in Learning, 91-110.

Howard, T. C. (2019). Why race and culture matter in schools: Closing the achievement gap in America's classrooms. Teachers College Press.

Hoy, W. K., \& Tarter, C. J. (2018). The Potential of Computer-Mediated Internship for Higher Education. International Journal of Educational Management, 1-13.

Ismail, J. (2007). Challenges in International Business Communication. A Study of Language, Culture and Inter-Cultural issues in Malaysian-Australian Business Discourse. University of Western Australia.

Johnston, K., Hadley, F., \& Waniganayake, M. (2020). Practitioner inquiry as a professional learning strategy to support technology integration in early learning centres: Building 
understanding through Rogoff's planes of analysis. Professional Development in Education, 46(1), 49-64. https://doi.org/10.1080/19415257.2019.1647871

Keats, D. M., \& Keats, D. (1997). Culture and the child: A guide for professionals in child care and development. Chichester, UK: Wiley.

Littleton, K. (1999). Learning together: Understanding the processes of computer-based collaborative learning. Collaborative Learning-Cognitive and Computational Approaches.

Malaysian Communications and Multimedia Commission. (2017). Section 3: Main Findings. Internet Users Survey 2017, 8-34.

http://search.proquest.com/docview/1477205997?accountid=14744\%5Cnhttp://fama.us. es/search*spi/i?SEARCH=18434711\%5Cnhttp://pibserver.us.es/gtb/usuario_acceso.php?c entro $=\$$ USEG\&centro $=\% 24 U S E G \& d=1$

Martini, M. (1996). 'What's New?' at the Dinner Table: Family Dynamics During Mealtimes in Two Cultural Groups in Hawaii. Early Development and Parenting, 5(1), 23-34. https://doi.org/10.1002/(sici)1099-0917(199603)5:1<23::aid-edp111>3.3.co;2-4

Matthews, R. (1996). The relationship between ethnic origin and learning styles and the implications for classroom practice. European Journal of Intercultural Studies, 6(3), 3-13. https://doi.org/10.1080/0952391960060301

McAlpine, L., Eriks-Brophy, A., \& Crago, M. (1996). Teaching Beliefs in Mohawk Classrooms: Issues of Language and Culture. Anthropology \& Education Quarterly, 27(3), 390-413. https://doi.org/10.1525/aeq.1996.27.3.04x0355q

McDonald, P. (1995). Australian families: values and behaviour. Robyn Hartley (ed).

MCMC Survey. (2017). Internet Users Survey 2017 - statistical brief number twenty-one. Malaysian Communications and Multimedia Commission, 1-52. https://doi.org/ISSN 18232523

Mehan, H. (1979). "What Time Is It, Denise?”: Asking Known Information Questions in Classroom Discourse. Theory Into Practice, 18(4), 285-294. https://doi.org/10.1080/00405847909542846

Mercer, N. (1994). The quality of talk in children's joint activity at the computer. Journal of Computer Assisted Learning, 10(1), 24-32. https://doi.org/10.1111/j.13652729.1994.tb00279.x

Mercer, Neil, \& Fisher, E. (1992). How do teachers help children to learn? An analysis of teachers' interventions in computer-based activities. Learning and Instruction, 2(4), 339-355. https://doi.org/10.1016/0959-4752(92)90022-E

Mercer, Neil, Wegerif, R., \& Dawes, L. (1999). Children's talk and the development of reasoning in the classroom. British Educational Research Journal, 25(1), 95-111. https://doi.org/10.1080/0141192990250107

Morris, M. G., Venkatesh, V., \& Ackerman, P. L. (2005). Gender and Age Differences in Employee Decisions About New Technology: An Extension the Theory of Planned Behavior. IEEE Transactions on Engineering Management, 52(1), 69-84.

Nastasi, B. K., \& Clements, D. H. (1993). Motivational and social outcomes of cooperative computer education environments. Journal of computing in childhood Education, 4(1), 1543. 
National Information Technology Council of Malaysia-Progress Report. (2002). National IT Agenda.

Otto, W. J. (2016). What Teachers Should Know about Why These Students Perform so Well: An Examination of Korean-American Achievement through Student Perspectives of East Asian Parenting Beliefs, Styles and Practices. International Electronic Journal of Elementary Education, 9(1), 167-181.

http://search.ebscohost.com/login.aspx?direct=true\&db=eric\&AN=EJ1126677\&site=ehost -live

Papps, F., Walker, M., Trimboli, A., \& Trimboli, C. (1995). Parental Discipline in Anglo, Green, Lebanese, and Vietnamese Cultures. Journal of Cross Cultural Psychology, 26(1), 49-64.

Pomerleau, A., Malcuit, G., \& Sabatier, C. (1991). Child-rearing practices and parental beliefs in three cultural groups of Montréal: Québécois, Vietnamese, Haitian

Ray, K., \& Smith, M. C. (2010). The kindergarten child: What teachers and administrators need to know to promote academic success in all children. Early Childhood Education Journal, 38(1), 5-18. https://doi.org/10.1007/s10643-010-0383-3

Rogoff, B. (1994). Rogoff_CommunitiesLearners_1994.pdf. In Mind, Culture, and Activity (Vol. 1, Issue 4, pp. 209-229).

Rogoff, B. (1998) Cognition as a Collaborative Process. In W. Damon, (Chief Editor) and D. Kuhn, \& R.S. Siegler, (Volume Eds.) Cognition, perceptions and language, $5^{\text {th }}$ Edition. Handbook of Child Psychology. NY: John Wiley \& Sons, Inc.

Rogoff, B. (2003). Orienting Concepts and Ways of Understanding the Cultural Nature of Human Development. In The Cultural Nature of Human Development.

Rogoff, B., Baker-Sennett, J., Lacasa, P., \& Goldsmith, D. (1995). Development through participation in sociocultural activity. New Directions for Child and Adolescent Development, 1995(67), 45-65. https://doi.org/10.1002/cd.23219956707

Rogoff, B., Mistry, J., Goncu, A., Mosier, C., Chavajay, P., Heath, S. B., \& Goncu, A. (1993). Guided Participation in Cultural Activity by Toddlers and Caregivers. Monographs of the Society for Research in Child Development, 58(8), i. https://doi.org/10.2307/1166109

Rogoff, B., \& Toma, C. (1997). Shared thinking: Community and institutional variations. Discourse Processes, 23(3), 471-497. https://doi.org/10.1080/01638539709545000

Rogoff, B., Topping, K., Baker-Sennett, J., \& Lacasa, P. (2002). Mutual contributions of individuals, partners, and institutions: Planning to remember in Girl Scout cookie sales. Social Development, 11(2), 266-289. https://doi.org/10.1111/1467-9507.00198

Sato, M. (2017). Interaction Mindsets, Interactional Behaviors, and L2 Development: An Affective-Social-Cognitive Model. Language Learning, 67(2), 249-283. https://doi.org/10.1111/lang.12214

Smagorinsky, P. (2012). Vygotsky, Defectology and the Inclusion of People of Difference in the Broader Cultural Stream. Journal of Language Ad Literacy Education, 8(1), 1-25. http://jolle.coe.uga.edu

Soto, C. J., John, O. P., Gosling, S. D., \& Potter, J. (2011). Age Differences in Personality Traits From 10 to 65: Big Five Domains and Facets in a Large Cross-Sectional Sample. Journal of Personality and Social Psychology, 100(2), 330-348. https://doi.org/10.1037/a0021717 
Stenhouse, L. (1981). What Counts as Research? British Journal of Educational Studies, 29(2), 103-114. https://doi.org/10.1080/00071005.1981.9973589

Sulaiman, A., Jamsari, E. A., \& Noh, N. C. (2014). Islamic environment in child development according to the views of imam Al-Ghazali. Mediterranean Journal of Social Sciences, 5(29), 33-39. https://doi.org/10.5901/mjss.2014.v5n29p33

Niles, S. (1993). Achievement Goals and Means: A Cultural Comparison. The ANNALS of the American Academy of Political and Social Science, 503(1), 122-136.

Syed, M. (2017). Why Traditional Metrics May Not Adequately Represent Ethnic Minority Psychology. Perspectives on Psychological Science, 12(6), 1162-1165. https://doi.org/10.1177/1745691617709590

Watkins, M., Ho, C., \& Butler, R. (2017). Asian migration and education cultures in the Anglosphere. Journal of Ethnic and Migration Studies, 43(14), 2283-2299. https://doi.org/10.1080/1369183X.2017.1315849

Wellman, H. M., \& Estes, D. (1986). Early Understanding of Mental Entities: A Reexamination of Childhood Realism. Child Development, 57(4), 910. https://doi.org/10.2307/1130367

Winegar, L. T., \& Valsiner, J. (Eds.). (2013). Children's Development Within Social Context: Volume I: Metatheory and Theory: volume li: Research and Methodology (Vol. 2). Psychology Press.

Yin, R. K. (1994). Method in Evaluation Research. Evaluation Practice, 15(3), 283-290.

Zin, M. Z. M., Sakat, A. A., Ahmad, N. A., \& Bhari, A. (2013). Relationship Between the Multimedia Technology and Education in Improving Learning Quality. Procedia - Social and Behavioral Sciences, 90(InCULT 2012), 351-355. https://doi.org/10.1016/j.sbspro.2013.07.102 